\title{
Home range size and its development for fallow deer in the Blue Mountains, New Zealand
}

\author{
Graham NUGENT
}

Nugent G. 1994. Home range size and its development for fallow deer in the Blue Mountains, New Zealand. Acta theriol. 39: 159-175.

Fifty-nine fallow deer Dama dama dama (Linnaeus, 1758) fitted with radio collars were monitored in the Blue Mountains, Otago, New Zealand, between September 1985 and February 1988 to determine home range size and patterns of range development. Fallow deer occupy small annual ranges, averaging 66 ha for females and 189 ha for males (90\% isopleths calculated by the Harmonic Mean method). For resident animals the respective values were 50 ha and 127 ha. Bimonthly seasonal range size varied with sex, age-class and season, with different seasonal patterns for males and females. Only one adult female dispersed, and most females occupied the same core range throughout the period they were monitored. Some subadult females did move into new areas, by a process of range extension rather than a single dispersive range shift. In contrast most males monitored for more than 6 months shifted their range, but the distances between successive seasonal range centres never exceeded $2.6 \mathrm{~km}$ and could not be reliably distinguished from adult seasonal movements. The range stability and slow dispersal rates of fallow deer should make them easier to control than the other common introduced deer species in New Zealand, and should make it practical to have different management objectives and regimes for adjacent catchments in the Blue Mountains.

Manaaki Whenua - Landcare Research, P.O. Box 31-011, Christchurch, New Zealand

Key words: Dama dama, home range, dispersal, New Zealand

\section{Introduction}

Kild deer have scant respect for land-tenure boundaries. Their movement across these boundaries can complicate the management of adjacent lands with different management objectives. In the most straightforward example of this, deer throughout most of North America and Europe are managed primarily for hunting but often move from woodland sanctuaries out into agricultural crops, causng widespread damage (Matschke et al. 1984, Putman 1989, Conover and Decker 1991). Similarly, increases in the size of Scottish deer populations has seen deer move into new areas, to the detriment of commercial tree crops (Ratcliffe 1989). Intuitively, the problem will often be most severe along boundaries and wheie deer management objectives vary on a geographic scale smaller than the range sizes of individual deer. Just such a problem occurs in the $227-\mathrm{km}^{2}$ Blue Mountains Recreational Hunting Area (RHA) in Otago, New Zealand. The RHA 
contains plantations of introduced conifers (managed primarily for wood production) intermingled with substantial remnants of indigenous forest managed for conservation and recreation (Fig. 1). Throughout New Zealand introduced deer (and other mammalian herbivores) have severely modified most indigenous forests (see Wardle 1984 for a review). The fallow deer population in the Blue Mountains is therefore managed primarily to prevent deer damage to indigenous forests, but within that constraint, managers aim to improve opportunities for recreational hunting (Nugent and Mawhinney 1987). These apparently incompatible goals prompted managers and researchers to look at the feasibility of managing deer at different densities in the two forest types (high densities in the plantations, where conservation values are low; low densities in the indigenous forests, where conservation values are high).

The smallest area within which deer can be managed differently from those in an adjacent area depends, at least in part, on the range utilisation and movement patterns of the species concerned. Published information on range size and movements of fallow deer are scarce, though Chapman and Chapman (1975) presented some largely qualitative estimates for fallow in one locality in eastern England, and Putman (1986) described some preliminary results from studies in the New Forest of southern England, where deer densities are high. In contrast, deer densities in the Blue Mountains were moderate to low in the mid 1980s, having been progressively reduced by virtually unrestricted year-round commercial and recreational hunting since 1960 (Nugent 1988). Deer densities were highest in the indigenous forest areas $\left(10-20\right.$ deer $\left./ \mathrm{km}^{2}\right)$ but were usually low in the plantation forest (1-5 deer $/ \mathrm{km}^{2}$ ), mainly as a consequence of the easy hunter access provided by a network of forestry roads (Nugent 1988).

A 2.5 year radiotracking study of deer movements was therefore undertaken in part of the RHA. This paper gives home range sizes for the fallow deer in this area, and describes patterns of range development for different sex and age-class groupings within the population. These results were used to ascertain the minimum area (management unit) needed for markedly different management regimes to be successful in adjacent areas within the RHA. Wild deer also have the potential to spread diseases such as bovine tuberculosis, so the implications of these results are also explored briefly in the context of the deer control required to prevent such disease spread.

\section{Study area}

The $227-\mathrm{km}^{2}$ Blue Mountains RHA ( $\left.45^{\circ} 57^{\prime} \mathrm{S}, 169^{\circ} 22^{\prime} \mathrm{E}\right)$ contains approximately $85 \mathrm{~km}^{2}$ of indigenous forest, mostly dominated by silver beech Nothofagus menziesii or shrub-hardwood species (Fig. 1). The $10.5 \mathrm{~km}^{2}$ in plantation forest is dominated by Pinus radiata and varies in stature from tall closed-canopy forest to newly planted forest less than $1 \mathrm{~m}$ tall. A third vegetation type, the unforested subalpine zone, is seldom used by deer because of the lack of cover and their resulting vulnerability to hunting. 
The fallow deer population is descended from 13 deer liberated between 1869 and 1871 (Baker 1972). Although the population subsequently reached high densities, these had been much reduced by

Fig. 1. The Blue Mountains Recreational Hunting Area, showing the distribution of the main vegetation types and the location of the study catchment.
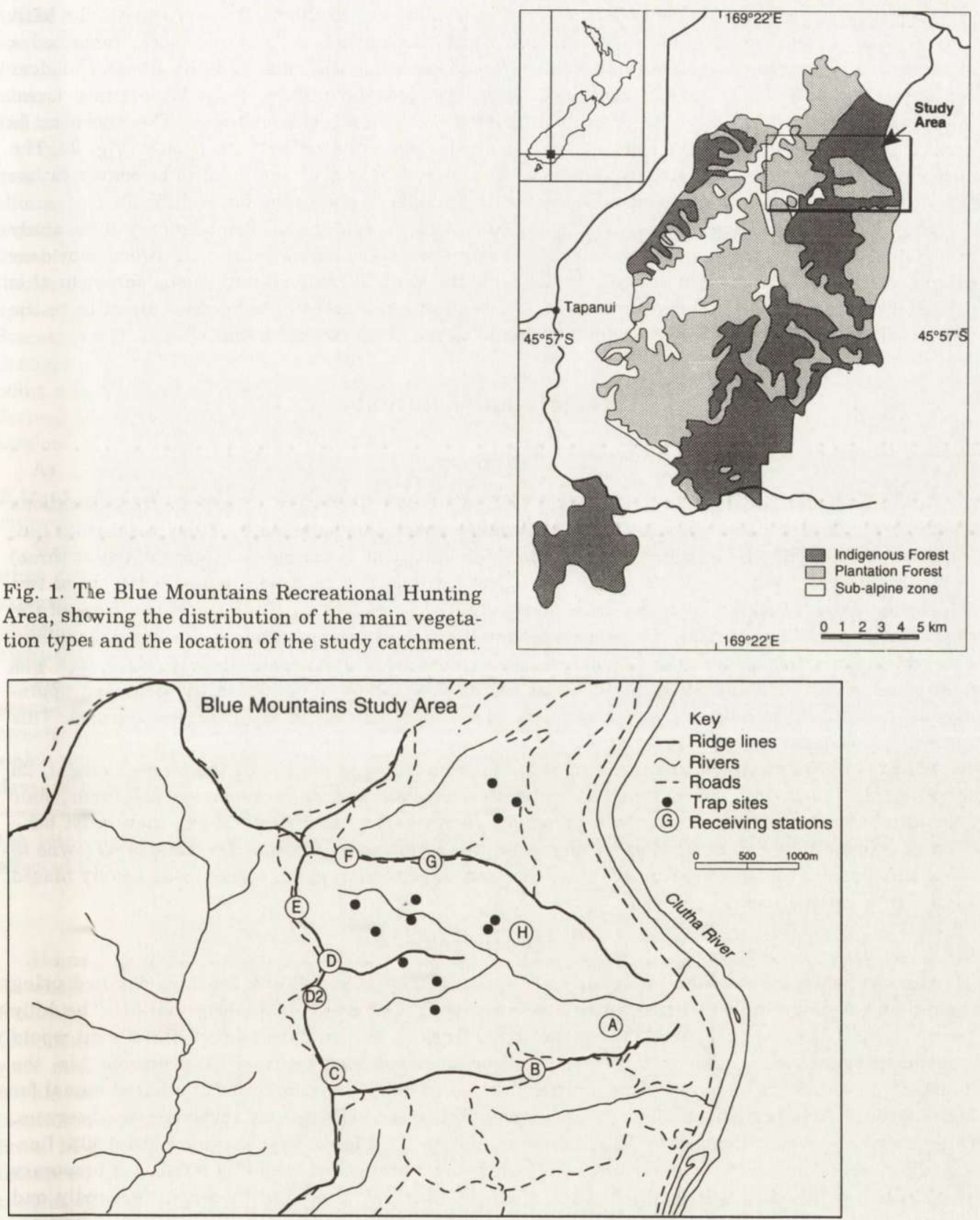

Fig. 2. The study catchment, showing the location of trap sites, the sites regularly visited with the mobile reeiver $(A-G)$, the fixed receiving site $(H)$, and the main ridges, creeks, and roads. 
the mid 1980s (Nugent 1988). As a consequence, present deer reproductive rates are high, and nearly all deer deaths result from hunting rather than from malnutrition or disease (Baker 1973, G. Nugent unpubl.).

The study was mainly conducted in the Tramways catchment in the northwest corner of the RHA (Figs 1 and 2). This small (456 ha) catchment, which constituted one hunting block, contained a mixture of indigenous and plantation forest. Unpublished harvest data and the number of deer captured suggested the catchment contained about 100 deer during the study. Well-formed forest roads provide good access to vantage points around the catchment's circumference. The catchment is divided into north and south branches by a central ridge running half its length (Fig. 2). The moderately steep valley sides rise from $30 \mathrm{~m}$ a.s.l. to over $600 \mathrm{~m}$ a.s.l. and tend to be convex rather than concave, which sometimes made observation of animals on the valley floors difficult.

The Clutha River (a fast flowing river up to $100 \mathrm{~m}$ wide) formed the eastern boundary of the study area. Other boundaries were determined by the maximum distance travelled in that direction by deer caught within the Tramways catchment. Though the central area of indigenous forest in this catchment is surrounded by plantation forest, other substantial areas of indigenous forest lie to the south (within $1 \mathrm{~km}$ ), to the west (within $2 \mathrm{~km}$ ), and to the north (within $5 \mathrm{~km}$ ).

\section{Materials and methods}

\section{Trapping}

Between September 1985 and February 1988, 59 fallow deer were caught in traps (locations shown in Fig. 2) and fitted with $160 \mathrm{MHz}$ VHF radiotransmitters supplied by Titley Electronics Ltd, Blenheim, New Zealand. Most deer were caught (individually or sometimes in groups of two or three) in seven pens (enclosures with 70-100 m circumferences and 2-m high wire fences, with one or two self-closing gates activated by a trip wire). Only eight were caught by three small box traps of the type described by Clover (1956). Traps were set for 10-12 days each month and checked daily from a 1-3 km distance using binoculars. Pens containing deer were approached quietly. Each deer was quickly restrained (usually by cornering it in the narrow raceways built into the pens), an appropriately-sized click-on radiocollar attached, and the animal carried to the gate and released. This process seldom took more than 2 minutes.

Most deer (75\%) were caught in the first 2 days of a trapping period. Of the 59 deer caught, 26 were female ( 18 fawns, three subadults, and five adults), and 33 were males ( 27 fawns, four subadults, and two adults). As fallow deer seldom twin (Stérba and Klusak 1984), there must have been at least as many adult females as there were fawns in the population. The ratio of 47 fawns to five adult females among the captured deer therefore indicates trapping success was heavily biased in favour of younger deer.

\section{Radiotelemetry}

The location of radiocollared animals was determined by triangulating bearings obtained using ground-based radioreceivers fitted with direction-finding 7-element double-yagi aerials. The hilly terrain initially caused problems because the signal from an animal not in direct line-of-sight would frequently bounce off a nearby hill-side, resulting in a spurious bearing. To overcome this, the following procedure was adopted: The aim was to obtain a single location for each collared animal for each of 10-12 days per month during a single monitoring session each day involving two observers. One observer was positioned in a fixed receiving station (H, Fig. 2) that provided about $80 \%$ line-of-sight coverage of the Tramways catchment, while the other visited each of a number of temporary sites with a trailer-mounted receiver (sites A-G, Fig. 2). The "fixed site" observer repeatedly and systematically obtained bearings for all collared deer, producing up to eight bearings per animal per session, noted the time, signal strength and steadiness of the signal, and subjectively assessed the apparent precision of each recorded bearing. The "mobile" observer attempted to obtain one bearing 
for each animal from each of the temporary stations, and noted the time and signal quality for each bearing.

Two female deer were not relocated by radiotelemetry, presumably as a consequence of transmitter failure. Another five deer (four female, one male) were shot or disappeared (presumably shot) soon after capture. The remaining 52 were relocated on at least 20 occasions, and were monitored for 2 or more months. Because many of these deer were not trapped until well into the study period, and many were shot or ceased transmitting during the study, only 29 were monitored for $>12$ months, and only seven for $>24$ months. Just one deer was monitored for the entire 30 -month study.

Animal locations were determined by manually plotting all bearings for each animal on a large map. Obviously spurious readings caused by signal bounce (perhaps $20 \%$ of all recordings) were eliminated, then the best of the remaining bearings were chosen using criteria such as strength, precision, and whether they made sense when related to the other bearings for that animal. Usually three (or more) of the "best" bearings formed a triangle of less than 10 ha (frequently $<5$ ha), and the centre of that triangle was chosen as the animal locus for the day. Where only two bearings appeared suitable, the intersection point of the two bearings provided the locus for that day. Sometimes the multiple observations from the fixed site indicated the animal had substantially changed its location ( $>200 \mathrm{~m}$ ) during a session, and two clearly separate locations were recorded. A point midway between the two locations was chosen as the single locus for the day. The loci thus derived should be regarded as the average position of the animal during the 3-5 hour monitoring session.

As a check on the reliability of this approach, observers were required to determine the location of transmitters placed at 20 representative positions in the Tramways catchment. In all 20 tests, the estimated locations were within $150 \mathrm{~m}$ of the actual location, and 19 were within $100 \mathrm{~m}$.

Monitoring sessions were usually conducted during mid morning (09.00-13.00), the time of day when deer were least mobile. During the few experimental evening and night sessions conducted, we experienced far greater difficulty in locating animals because their greater mobility at those times caused the radio signals to fluctuate widely. These sessions did, however, establish that day- and night-time locations were similar (i.e. the deer did not show major diurnal shifts in range).

For some deer, a combination of weak signals (as batteries began to run down) and their use of areas out of direct line-of-sight from receiving sites, resulted in such imprecise bearings that we were sometimes unable to quantify their positions even though we often knew which catchment (or even which part of a catchment) they were in. In addition, some deer were not recorded at all for several days, either because of observer oversight or some combination of signal weakness and difficult-to-receive locations. As a result, for these deer, there were incomplete sequences of seasonal data within the total period they were monitored. These missing locations are unlikely to have significantly affected the estimates of range size. Overall, a total of 5716 locations were plotted.

\section{Estimation of home range size}

Home range size was determined for the entire period each animal was monitored (total range), for whole calendar years (annual range), and for bimonthly seasons within each year (seasonal range), Both the minimum convex polygon (MCP; Mohr 1947) and the harmonic mean (HM; Dixon and Chapman 1980) methods were used to calculate total and annual home range size. Six female fallow were monitored for two calendar years, and a further seven for at least one, giving 19 estimates of female annual home range size (two fawn, nine subadult, and eight adult; Table 1). Three males were monitored for 2 years, and a further 13 for 1 year, also giving 19 estimates of annual range size (three fawn, 12 subadult, and four adult; Table 1). To avoid repetition, only HM data is presented in most instances, but annual MCP range sizes are also presented because the MCP method has been widely used in other studies and is therefore likely to be useful for comparing between studies (Harris et al. 1990). However, the size of MCP estimates partly depends on sample size when the number of observations is less than 50-100 (Harris et al. 1990), and in this study all seasonal estimates were based on fewer than 25 observations, so only the HM method was therefore used to calculate seasonal 
range sizes. The degree to which deer locations were clustered around a core annual range was investigated by comparing annual MCP range size with the 50,60,70,80, 90, and $100 \% \mathrm{HM}$ isopleths (i.e. the area enclosed within the boundary calculated to contain the respective percentage of the total number locations for each animal). Only the $50 \%$ and $90 \%$ values are reported.

Bimonthly seasons were chosen because they are most relevant to the fallow year, which in New Zealand begins with the fawning season in December and January. For this paper consecutive 2-month periods after the fawning season were classified as summer (late summer - early autumn), rut, winter, late winter (which includes early spring), and spring seasons. The seasonal and annual ranges are categorised by sex and age-class [fawn (< yr); subadult (1-2 yr); adult (2 yr)]. Season, age-class, and sex effects on the various estimates of home-range size and shifts (see below) were assessed using least squares two- or three-factor ANOVA (to allow for unbalanced sample sizes) and data were log transformed to stabilise variances. Deer were classified as resident if all the seasonal ranges for the year overlapped with the first one recorded, and as non-resident if they did not.

\section{Range shifts and dispersal}

For each deer monitored for more than 1 season ( 2 months), the distance between successive seasonal range centres (as calculated by the HM method) was determined. These data were compared between sexes and seasons to assess the scale and timing of range shifts. In previous investigations of deer movements in New Zealand (Gibb and Flux 1973, Davidson 1979), self-attaching collars were used to mark deer. These collars were later recovered, usually when the deer were shot, and the distance between the marking and recovery locations was calculated. For comparison with these studies, the distance between first and final observed locations was calculated for each deer monitored for one or more seasons in this study.

\section{Results}

\section{Annual and total home range size}

The two methods for calculating annual range size gave broadly similar results in most instances, with (as intuitively expected) the 90\% HM estimates usually being somewhat smaller than the MCP estimates (Table $1 ; \bar{x}=131$ and 152 ha, respectively). However, for 16 (42\%) of the 38 annual ranges calculated, the MCP estimate was more than one third larger than the $90 \%$ HM estimate, typically as a result of dispersal event or a brief foray by an animal away from its core range. This reflects the heavy dependence of MCP estimates to the position of a few outer locations (Harris et al. 1990).

Neither sex used their annual ranges uniformly. Core annual ranges (50\% HM) were, on average, only $20 \%$ of the $90 \%$ HM ranges and $13 \%$ of the MCP range for females and $16 \%$ and $15 \%$, respectively, for males (Table 1). Male range sizes were, on average, 2-3 times larger than those of females (Table $1 ; p<0.001$ in each of the separate ANOVAs for MCP, 50\% HM and 90\% HM estimates). There were no significant differences between age-classes in the mean MCP and 90\% HM range sizes ( $p=0.42$ and 0.08 respectively), but the core $50 \% \mathrm{HM}$ range sizes increased significantly with age ( $p=0.005$; fawn, subadult, and adult mean $50 \%$ HM ranges sizes of 5,14 , and 17 ha for females and 10, 28, 40 ha for males 
Table 1. Annual MCP and HM home range sizes for deer by sex and age-class. All ranges were calculated for 12-month periods approximately aligned with calendar years. Few fawns are represented because few were caught in their first season of life. Asterisks in the "Deer \#" column denote which deer were classified as resident during the year for which the annual ranges shown were calculated.

\begin{tabular}{|c|c|c|c|c|c|c|}
\hline \multirow{2}{*}{ Sex } & \multirow{2}{*}{$\begin{array}{l}\text { Age class } \\
\text { at capture }\end{array}$} & \multirow{2}{*}{ Deer \# } & \multirow{2}{*}{$\begin{array}{l}\text { No. } \\
\text { locations }\end{array}$} & \multicolumn{3}{|c|}{ Annual home range size (ha) } \\
\hline & & & & MCP & $50 \% \mathrm{HM}$ & $90 \% \mathrm{HM}$ \\
\hline \multirow[t]{19}{*}{ Female } & Fawn & $15^{*}$ & 101 & 39 & 6 & 37 \\
\hline & Fawn & $17^{*}$ & 106 & 94 & 4 & 33 \\
\hline & Subadult & $41^{*}$ & 108 & 40 & 7 & 24 \\
\hline & Subadult & $11^{*}$ & 100 & 49 & 14 & 43 \\
\hline & Subadult & $28^{*}$ & 87 & 50 & 10 & 43 \\
\hline & Subadult & $18^{*}$ & 126 & 55 & 6 & 27 \\
\hline & Subadult & $22^{*}$ & 116 & 95 & 8 & 45 \\
\hline & Subadult & $10^{*}$ & 129 & 100 & 17 & 71 \\
\hline & Subadult & $17^{*}$ & 107 & 111 & 19 & 89 \\
\hline & Subadult & $15^{*}$ & 75 & 115 & 8 & 57 \\
\hline & Subadult & $3^{*}$ & 113 & 191 & 18 & 113 \\
\hline & Adult & $24^{*}$ & 109 & 31 & 6 & 27 \\
\hline & Adult & $16^{*}$ & 103 & 37 & 8 & 31 \\
\hline & Adult & $16^{*}$ & 113 & 39 & 6 & 39 \\
\hline & Adult & $44^{*}$ & 109 & 40 & 11 & 29 \\
\hline & Adult & $11^{*}$ & 91 & 56 & 13 & 48 \\
\hline & Adult & $18^{*}$ & 87 & 65 & 8 & 34 \\
\hline & Adult & $3^{*}$ & 105 & 143 & 31 & 107 \\
\hline & Adult & 6 & 112 & 527 & 53 & 362 \\
\hline \multirow{2}{*}{\multicolumn{2}{|c|}{ All females }} & \multirow{2}{*}{\multicolumn{2}{|c|}{$\begin{array}{l}\bar{x} \\
\mathrm{SD}\end{array}$}} & 99 & 13 & 66 \\
\hline & & & & 109 & 11 & 74 \\
\hline \multirow{19}{*}{ Male } & Fawn & $23^{*}$ & 90 & 77 & 12 & 49 \\
\hline & Fawn & $47^{*}$ & 83 & 114 & 11 & 110 \\
\hline & Fawn & 20 & 88 & 177 & 6 & 58 \\
\hline & Subadult & $8^{*}$ & 123 & 76 & 9 & 40 \\
\hline & Subadult & $38^{*}$ & 70 & 96 & 18 & 104 \\
\hline & Subadult & 30 & 72 & 111 & 22 & 86 \\
\hline & Subadult & 34 & 68 & 130 & 30 & 159 \\
\hline & Subadult & $20^{*}$ & 69 & 133 & 18 & 134 \\
\hline & Subadult & 39 & 110 & 173 & 34 & 143 \\
\hline & Subadult & $4^{*}$ & 131 & 208 & 26 & 204 \\
\hline & Subadult & 35 & 73 & 212 & 33 & 150 \\
\hline & Subadult & 25 & 108 & 259 & 23 & 75 \\
\hline & Subadult & 23 & 67 & 275 & 52 & 388 \\
\hline & Subadult & 32 & 90 & 291 & 34 & 327 \\
\hline & Subadult & $2 *$ & 112 & 316 & 43 & 261 \\
\hline & Adult & $8^{*}$ & 71 & 121 & 11 & 111 \\
\hline & Adult & 14 & 112 & 210 & 47 & 205 \\
\hline & Adult & 33 & 102 & 286 & 40 & 256 \\
\hline & Adult & 27 & 75 & 621 & 99 & 599 \\
\hline \multirow[t]{2}{*}{ All males } & & \multirow{2}{*}{\multicolumn{2}{|c|}{$\begin{array}{l}\bar{x} \\
\mathrm{SD}\end{array}$}} & 206 & 31 & 189 \\
\hline & & & & 126 & 21 & 135 \\
\hline
\end{tabular}


respectively). There were no significant interactions between age-class and sex effects in any of these analyses.

The overall female range size means in Table 1 are misleading, because they include one female (\#6) that moved to a completely new range during the study, almost certainly as a consequence of excessive disturbance. Its initial range during the 8 months after capture was entirely within $0.3 \mathrm{~km}$ of the fixed receiving station (Fig. 5c). Nine months after initial capture, this deer was recaptured and released, then a few days later was chased by a dog for several hours, after which it moved to new range. Although this deer had survived at least 5 years (presumably mostly in its initial range), it was shot 6 months after moving to unfamiliar terrain, an indication of the dangers of dispersal. The two next largest female annual ranges were for female \#3 (monitored in both its subadult and first adult year), which

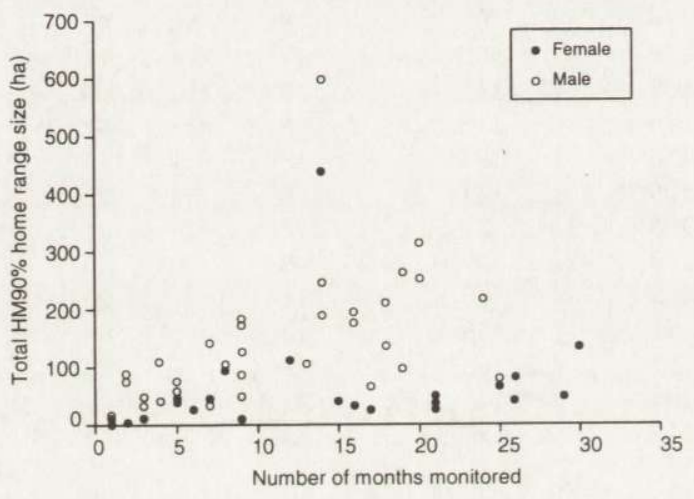

Fig. 3. Relationship between total $90 \%$ HM range size and the period a deer was monitored, by sex.

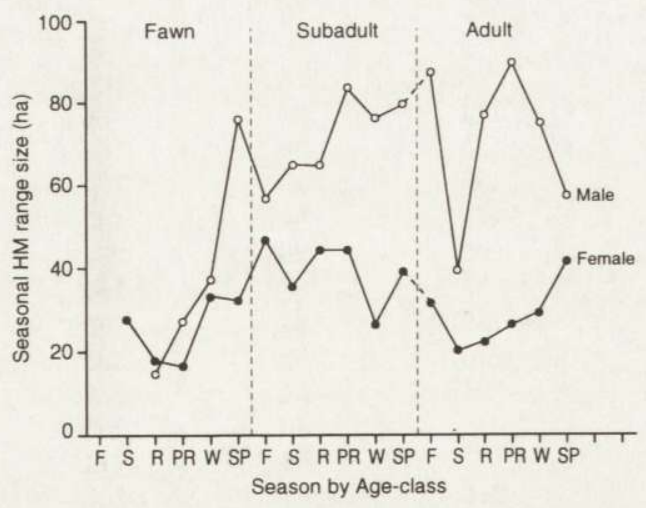

Fig. 4. Variation in mean seasonal $90 \%$ HM range size, by sex, age-class, and season. Abbreviations for seasons along the $x$ axis are: $\mathrm{F}$ - fawning, $\mathrm{S}$-summer, $\mathrm{R}$ - rut, $\mathrm{PR}$ - post rut, $\mathrm{W}$ - winter, $\mathrm{SP}$ - spring. had two regularly visited centres of activity about $1 \mathrm{~km}$ apart. All other females appeared to have a single main centre of activity and had annual $90 \% \mathrm{HM}$ ranges of less than 90 ha. For resident females (i.e. excluding \#6) the annual $90 \%$ HM ranges averaged $50(\mathrm{SD}=27)$ ha. Resident subadult females had significantly larger annual 90\% HM ranges than resident adults $(\bar{x}=57$ and 45 ha, respectively, $t$-test, $p<0.05$ ).

The larger range sizes of males partly reflected the much higher percentage $(58 \%)$ of non-resident males than females (5\%). However, the average annual 90\% HM range size calculated for the eight males classified as resident $(\bar{x}=127, \mathrm{SD}=74 \mathrm{ha})$ was also more than double the resident female average.

The regular monitoring schedule meant there was a close correlation between the number of bearings obtained for each deer and the length of time over which those bearings were obtained $(r=0.97, \mathrm{df}=57, p<0.001)$. The plots of total 90\% HM range against monitored period (Fig. 3) and of total $90 \% \mathrm{HM}$ range size against the number of locations obtained per 
individual were therefore very similar. For females, the estimates of total $90 \%$ HM range size reached an asymptote after the deer had been monitored for about 6 months (70-80 locations), indicating that this period (and number of locations) is the minimum required to estimate annual and lifetime range sizes for females. In contrast, there was no evidence of an asymptotic total $90 \% \mathrm{HM}$ range size for males in relation to either the monitored period (Fig. 3) or the number of locations obtained per deer, indicating less range stability in males than in females. The lifetime range size achieved by males was dependent more on how long they survived. The average age at death for males in the RHA was $1.5 \mathrm{yr}$ (cf $2.9 \mathrm{yr}$ for females; G. Nugent, unpubl.), making it likely that spread of total $90 \%$ HM range sizes in Fig. 3 is roughly representative of the variation in the lifetime range sizes actually achieved during the truncated life spans of male fallow deer in the Blue Mountains.

\section{Seasonal changes in range size}

The overall mean seasonal $90 \%$ HM range size for females was 31 ha $(\mathrm{SD}=30$, $n=146$; Fig. 4). Compared with the mean annual $90 \%$ HM range for resident females of 51 ha $(\mathrm{SD}=21)$, this indicates that, on average, females used about $60 \%$ of their annual range in any 1 season. For males, seasonal $90 \%$ HM range size averaged 60 ha ( $\mathrm{SD}=57, n=159$; Fig. 4), less than one-third the mean annual $90 \% \mathrm{HM}$ range size $(\bar{x}=189, \mathrm{SD}=135)$.

Seasonal 90\% HM range sizes differed significantly between the sexes $(p<0.001)$, age-classes $(p<0.001)$, and seasons ( $p=0.001$; Fig. 4$)$. The difference in seasonal range size between the sexes was similar in magnitude to that for annual range size, a further indication that the greater range size of males was not just a consequence of seasonal range shifts, but also reflected a tendency to move more widely on a day-to-day basis. Variation in seasonal range size for age-classes also differed between the sexes $(p=0.008)$. For females, adults and fawns had similar mean seasonal range sizes (undoubtedly reflecting the linkage between fawns and their mothers), but subadult mean seasonal range was nearly 1.5 times larger; for males, adult and subadult mean seasonal range sizes were similar and more than double that of fawns (Fig. 4). These sexual and age-class differences meant seasonal range sizes were similar for the two sexes only during the first part of their fawn year (Fig. 4).

\section{Individual patterns of range development}

Female ranges were generally stable throughout the monitoring period (Fig. 5). For the 18 females monitored over three or more seasons (6 months), successive $90 \%$ HM seasonal ranges nearly always overlapped by more than $25 \%$. For $72 \%$ of the females, all their 90\% HM seasonal ranges calculated included the centre of activity calculated for the entire period they were monitored. 

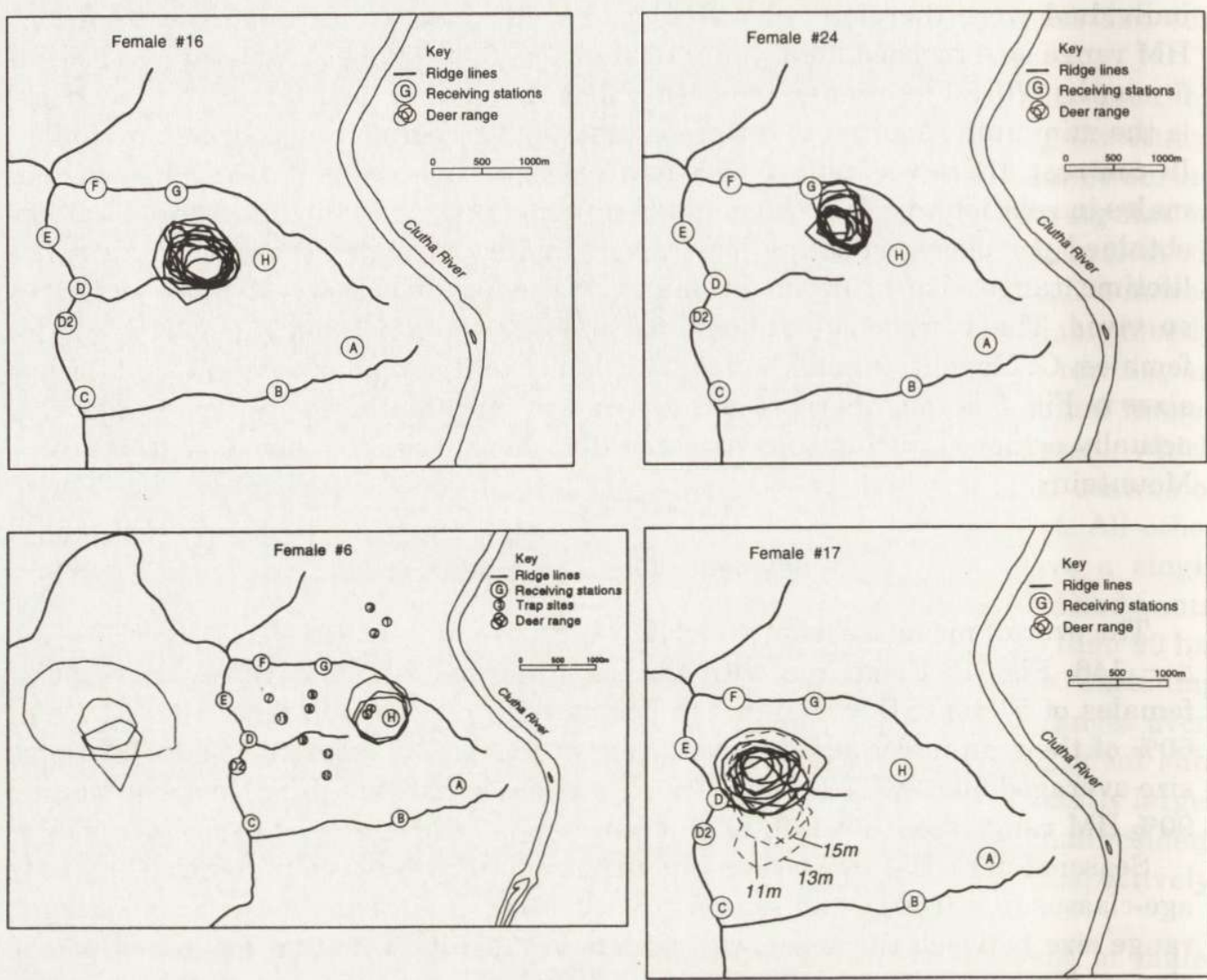

Fig. 5. Representative examples of female range use patterns; \#16 - adult, \#24 - subadult, \#6 - the sole adult female disperser, \#17 - fawn showing range extension. The ranges shown are mostly successive $90 \%$ HM seasonal ranges, but a few ranges not affecting the overall pattern have been omitted to aid visual clarity. For key ranges, the time of year or average age (in months) of the animal is shown.

The six females captured as subadults or adults showed little variation in range between seasons for the entire period they were monitored (e.g. Adult \#16, Fig. $5 \mathrm{a}$; Subadult \#24, Fig. 5b), and only the one adult (female \#6) shifted to a completely new area (Fig. 5c). None of the 12 females captured as fawns shifted to entirely new range by what could be clearly identified as single dispersal events, and of the seven of these twelve that were monitored into adulthood four retained almost exactly the same range. However, the other three appeared to partially disperse by a process of range "drift" in one direction over several seasons so that eventually their ranges included less than half the natal range. This process started either at the end of their first year or early in their subadult year. Some females captured as fawns similarly extended their range at about the same age, but subsequently settled back into their natal ranges (e.g. \#17; Fig. 5d). 

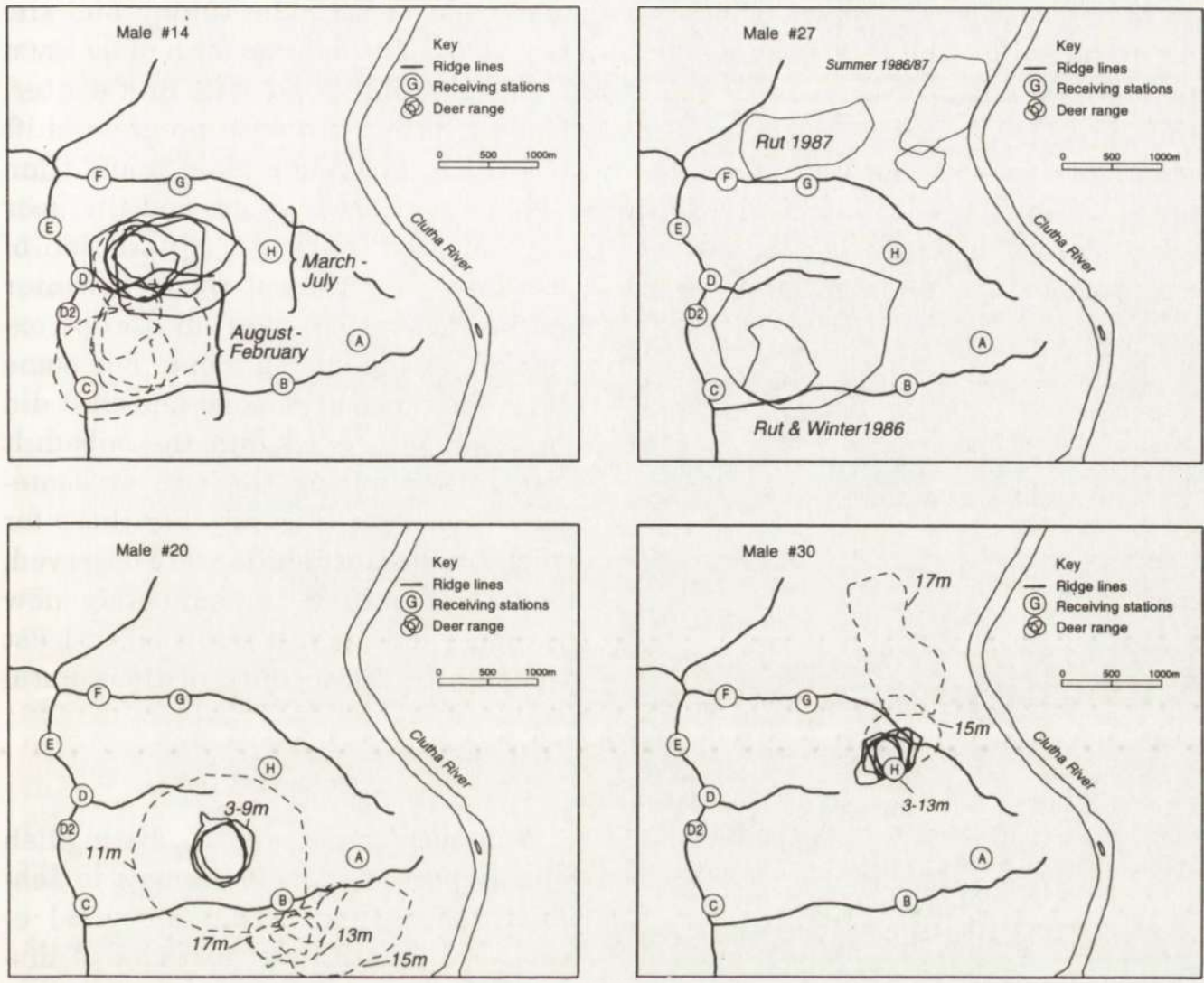

Fig. 6. Examples of male ranges: \#14 - adult, \#27 - adult, \#20 - fawn/subadult, \#30 - fawn/subadult. See Fig. 5 legend for explanations of format, data type, and range labels.

Male ranges were far less stable than those of females. Only eight (35\%) of 23 males monitored for 6 months occupied final 90\% HM seasonal ranges that also included some of the $90 \%$ HM seasonal range in which they were initially monitored. For 19 males successive seasonal range centres were outside the preceding $90 \% \mathrm{HM}$ range at least once, and, for seven of these, twice or more during the monitored period. The four males that did not follow this pattern were not monitored for a full year, so that the lack of observed range shifts may have reflected the limited monitoring period.

Only three males were captured as subadults or adults, but all three shifted range at least twice during the period they were monitored (e.g. \#14 - Fig. 6a, \#27 - Fig. 6b). Male \#14 occupied the same range during successive ruts, whereas male \#27 used different ranges in the ruts of 1986 and 1987. 
Males captured as fawns showed wide variation in both the timing and the nature of shifts. The most common pattern (e.g. \#20 - Fig. 6c) was for a male fawn to maintain a relatively stable "female-sized" range until the end of its first winter, then greatly expand its range in all directions in spring, but with no great shift in range centre. About the time of the next fawning, the young male would then abruptly shift $1.0-1.5 \mathrm{~km}$. The new range seldom appeared stable, and the deer often shifted again during the rut, or greatly enlarged its range. A variation of this pattern was for a gradual expansion of range after the rut through winter

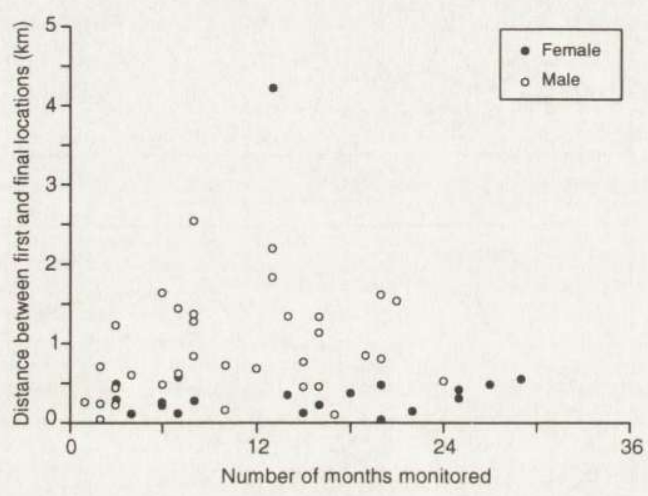

Fig. 7. Distances between first and final locations, by sex, in relation to the period each animal was monitored

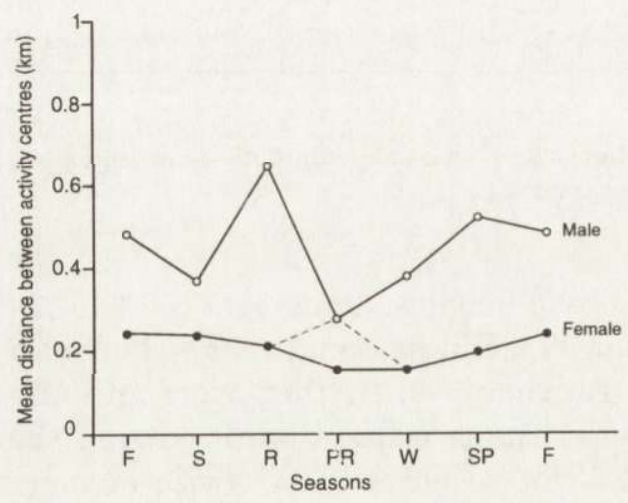

Fig. 8. Mean distances between successive seasonal range centres by sex and season. The range centre movements relate to changes between the designated season and its predecessor and the abbreviations for seasons along the $x$ axis match those in Fig. 4. For females, means were first calculated with the disturbance-induced dispersal of female \#6 omitted (solid line) and then with that data included (dashed line). and spring, rather than an abrupt expansion during spring alone. For some males the range expansion and shift did not begin until well into the subadult year, either during the rut, or sometimes even later (Fig. 6d). For those for which two distinct shifts were observed, about half shifted to completely new locations, and the rest returned, at least partially, to the vicinity of their natal ranges.

\section{Dispersal}

It proved impossible to distinguish reliably between small changes in seasonal ranges and actual dispersal events, so quantitative averages of dispersal distances per se cannot be given. However, the distances between first and final locations indicate that dispersal distances for fallow must be small. For females, there were no long-distance movements $(1 \mathrm{~km})$ that could indisputably be classed as dispersal events, except for female \#6 whose final location was $4.23 \mathrm{~km}$ from its initial capture site. For all other females, final locations were all within $0.67 \mathrm{~km}$ of initial capture sites $(\bar{x}=0.29, \mathrm{SD}=0.16$, $n=19$ (six females were monitored for less than 1 month)). The distance between first and last locations was not correlated with the length of time females were monitored (Fig. $7 ; r=0.08$, $\mathrm{df}=17, p>0.05$ ). For males, the maxi- 
mum distance between first and final locations was only $2.54 \mathrm{~km}(\bar{x}=0.92, \mathrm{SD}=$ $0.61, n=33$ ), with no overall apparent correlation between this distance and the period for which each animal was monitored (Fig. $7 ; r=0.33, \mathrm{df}=31, p>0.05$ ).

The distance between successive seasonal range centres provided an alternative measure of range stability. As expected, shifts in range centre between seasons for females were small (\#6 excluded; $\bar{x}=0.22 \mathrm{~km}, \mathrm{SD}=0.12 \mathrm{~km}, \max =0.77 \mathrm{~km}$ ). Nonetheless, activity centres for most females did change regularly between seasons. Male interseasonal distances were generally double those of females (Fig. 8).

\section{Conclusions}

\section{Home range size}

Assessing range size proved problematic for males because of the lack of any evidence for an asymptotic lifetime range size (Fig. 3). Using annual range size as a measure of spatial requirements is therefore somewhat meaningless for most male deer, because the range size recorded depends more on the scale and direction of any seasonal or dispersive movements undertaken than on the space actually utilised within seasons. The bimonthly seasonal ranges give a better picture of the area required by male deer to fulfil their day-to-day feeding and shelter requirements within seasons, but do not depict the space needed by males to find mates.

Blue Mountains female fallow seldom occupy more than 100 ha and male rarely more than 300 ha. Based on visual observations of individually identifiable animals, female fallow in the New Forest, southern England, had "full" MCP range sizes of 48-89 ha $(\bar{x}=69$ ha) over the May-October period (equivalent to late spring, fawning, and summer seasons in the southern hemisphere) (N. Rand in Putman 1986). The mean value is remarkably close to the mean annual MCP range size for resident females in this study ( $77 \mathrm{ha}$ ). Males in Rand's study had average range sizes of 107 ha over the May-September period, which increased to 153 ha over winter (range 55-260 ha.). Rand also noted the considerable individual variation and year-to-year change in range size observed in this study.

Home range estimates for non-migratory white-tailed deer Odocoileus virginianus in North America vary between 59 and 520 ha (Marchinton and Hirth 1984), with the majority of estimates above the 152 ha both-sex average recorded in this study. Estimates for European red deer Cervus elaphus range from an average annual size of 171 ha for non-migratory females in the European Alps (Georgii 1980) up to more than 6000 ha for migratory deer in Scotland (Staines 1974). In Denmark, average annual range size for undisturbed female red deer was 257 ha, and exceeded 760 ha for males (Jeppesen 1987). In Maryland, USA, Feldhammer et al. (1982) reported a range size of 182 ha for a 10-month-old male sika Cervus nippon monitored for 5 months and shot $4.3 \mathrm{~km}$ away two months after the study. 
A 10-month-old female sika deer monitored for two years occupied 127 ha in the same area. The home range estimates for fallow in Blue Mountains and in the New Forest therefore appear to be at the lower end of the spectrum of range sizes reported for medium- and large-sized deer species.

However, the patterns of range development and seasonal and age-class variation for fallow are similar to those reported for other deer species. Males have substantially larger ranges than females, are more likely to disperse from their natal range, and show less loyalty to any particular area. Male seasonal ranges are small while they are dependent on their mothers, but as that dependence progressively (or abruptly) lessens during their first year, range size increases substantially. Sexually mature males adopt large range sizes immediately after the rut rather than during the rut itself (Fig. 4), which may reflect males seeking out any unmated females or extensive feeding as males try to recover condition lost during the rut.

\section{Dispersal}

Large-scale one-directional movements that could be confidentially classed as dispersal were unusual. Frequently, what appeared to be a dispersal event for a male fawn (for example) was often smaller than the presumably seasonal range shifts practised by the few adult males monitored. The problem of recognising dispersal events was compounded by the high rate at which young male deer are shot by hunters in the Blue Mountains RHA. The few months many such deer were monitored was not long enough to indicate the likely extent of their potential dispersal. Some deer were shot as they shifted range, making it impossible to determine whether the shift was temporary or permanent.

No deer moved more than $4.23 \mathrm{~km}$ during this study. For male fawns, the group most likely to disperse, the distance between first and final location never exceeded $2.54 \mathrm{~km}$, and for $90 \%$ was less than $1.5 \mathrm{~km}$. In contrast, a study in New Zealand beech forest showed young red deer males can move up to $32 \mathrm{~km}$ (R. Taylor in Gibb and Flux 1973). Similarly, 54 sika deer marked with self-attaching snare collars in a New Zealand beech forest were recovered at distances up to $17.1 \mathrm{~km}$ from the marking site $(\bar{x}$, both sexes $=2.2 \mathrm{~km}$ ) (Davidson 1979). Dispersal distances exceeding $100 \mathrm{~km}$ have been reported for white-tailed deer in North America (Marchinton and Hirth 1984), and, unlike young female fallow in this study, about $20 \%$ of young female white-tailed deer may disperse (Nelson and Mech 1992). Fallow therefore seem to be one of the least dispersive deer species.

Although the most obvious evidence of actual dispersal was provided by young males, some young females did move to new ground by range drift, a process that probably reflects a gradual weakening of matrilineal bonds as individuals permeate into the wider population, as suggested by Albon et al. (1992). Any abrupt dispersal of female fallow deer in the Blue Mountains probably occurs only after catastrophic or excessive disturbance (e.g. being orphaned, repeatedly captured, or molested by dogs, as in this study). 
Fallow deer populations in New Zealand have been slower than other deer species in expanding their geographic range (Caughley 1963), presumably reflecting the limited tendency for females (in particular) to disperse observed in this study. Although fallow were successfully liberated in at least 24 locations in New Zealand, only 13 of these populations still remain, virtually all as discrete populations centred on the liberation points (Davidson and Nugent 1990). In contrast, the initial populations of red deer expanded and coalesced into what are effectively single populations within each of the three main Islands (Challies 1990).

\section{Management implications}

The small home range size and slow dispersal of fallow deer have several implications for their management in New Zealand, and in the Blue Mountains RHA specifically. This study was undertaken in one of the most densely populated catchments $\left(20 \mathrm{deer} / \mathrm{km}^{2}\right.$; G. Nugent, unpubl.) within the RHA, and it is unlikely that deer would ever be managed at densities very much higher than this. It therefore appears that, for the Blue Mountains at least and with the exception of a few males, most deer are likely to remain within the catchment in which they were born. Deer density in major catchments or management units within the RHA ( $>1000$ ha) will therefore usually be largely independent of deer density in adjacent areas. It should therefore be possible to manage adjacent units at very different densities, and, by doing so, partially resolve the conflict between hunting and conservation goals within the RHA. Maintaining moderate (ca $10-20$ deer $/ \mathrm{km}^{2}$ ) deer densities in the plantation forest areas, but low densities $\left(<2\right.$ deer/ $\left.\mathrm{km}^{2}\right)$ in the mainly indigenous forest, would conserve the hunting resource yet reduce the threat to indigenous conservation values. Present management is moving toward this regime (L. Freer, pers. comm.)

This study also has some implications for the control of deer to prevent spread of diseases such as bovine tuberculosis (Tb). In New Zealand deer are being increasingly implicated as one of several wildlife vectors capable of transmitting $\mathrm{Tb}$ - the disease was apparently brought into the previously Tb-free Mackenzie Basin in the central South Island by the translocation of infected domesticated deer (J. Coleman, pers. comm.). Fallow deer do contract Tb (Robinson et al. 1989), and several of New Zealand's fallow herds occur in areas where the disease is regarded as endemic (permanently established in livestock and wildlife). The slow spread of fallow deer (Caughley 1963) and short dispersal distances (this study) suggest they are unlikely to spread the disease rapidly. Nonetheless, the frequent range shifts by males provide a mechanism by which the disease could move through an established population. This study suggests that establishing and maintaining a deer-free buffer zone of about $4-5 \mathrm{~km}$ width between infected and uninfected fallow deer populations should be adequate to prevent disease spread by fallow, at least in habitats that parallel the Blue Mountains situation in terms of deer densities and availability of food and cover. 
If fallow deer elsewhere also have the small range sizes and short dispersal distances that this study suggests are typical of fallow in New Zealand, the species may be more easily managed in the developed landscapes of Europe than other more wide-ranging cervids, particularly if their apparently conservative use of space diminishes the conflicts between hunters, foresters, conservationists and farmers.

Acknowledgements: I thank the many volunteers, field assistants, and Department of Conservation staff involved in the telemetry study. Particular thanks go to R. Henderson and P. Sweetapple, who shouldered much of the burden of the tedious capture and monitoring programme. In addition I thank C. Frampton, B. Warburton, and J. Orwin for their comments on and assistance with early drafts. Initial fieldwork was funded by the New Zealand Forest Service, later work by the New Zealand Department of Conservation, and the final analysis and write up by the Foundation for Research, Science, and Technology.

\section{References}

Albon S. D., Staines H. J., Guiness F. E. and Clutton-Brock T. H. 1992. Density-dependent changes in spacing behaviour of female kin in red deer. J. Anim. Ecol. 61: 131-137.

Baker K. 1972. The history of the Blue Mountain fallow deer (Dama dama) herd. N. Z. Wildlife 38: 27-31.

Baker K. 1973. Reproductive biology of fallow deer (Dama dama) in the Blue Mountains of New Zealand. M.Sc. thesis, University of Otago, New Zealand: 1-147.

Caughley G. 1963. Dispersal rates of several ungulates introduced into New Zealand. Nature 200: 280-281.

Challies C. N. 1990. Red deer. [In: Handbook of New Zealand mammals. C. M. King, ed]. Oxford University Press, Auckland: 436-457.

Chapman D. I. and Chapman N. G. 1975. Fallow deer. Their history, distribution and biology. Terence Dalton Ltd., Lavenham, Suffolk: 1-271.

Clover M. R. 1956. Single-gate deer trap. Calif. Fish \& Game 42: 199-201.

Conover M. R. and Decker D. J. 1991. Wildlife damage to crops: perceptions of agricultural and wildlife professionals in 1957 and 1987. Wild. Soc. Bull. 19: 46-52.

Davidson M. M. 1979. Movements of marked sika (Cervus nippon) and red deer (Cervus elaphus) in central North Island, New Zealand. N. Z. J. For. Sci. 9: 77-88.

Davidson M. M. and Nugent G. 1990. Fallow deer. [In: Handbook of New Zealand mammals. C. M. King ed]. Oxford University Press, Auckland: 490-506.

Dixon K. R. and Chapman J. A. 1980. Harmonic mean measure of animal activity areas. Ecology 61: 1040-1044.

Feldhammer G. A., Dixon K. R. and Chapman J. A. 1982. Home range and movement of sika deer (Cervus nippon) in Maryland. Z. Säugetierk. 47: 311-316.

Georgii B. 1980. Home range patterns of female red deer (Cervus elaphus L.) in the Alps. Oecologia 47: $278-285$.

Gibb J. A. and Flux J. E. C. 1973. Mammals. [In: The natural history of New Zealand. G. R. Williams, ed]. Reed, Wellington: 334-371.

Harris S., Cresswell W. J., Forde P. G.. Trewhella W. J., Woollard T. and Wray S. 1990. Home-range analysis using radio-tracking data - a review of problems and techniques particularly as applied to the study of mammals. Mammal Rev. 20: 97-123.

Jeppesen J. L. 1987. Impact of human disturbance on home range, movements and activity of red deer (Cervus elaphus) in a Danish environment. Danish Rev. Game. Biol. 12(2): 1-38.

Marchinton R. L. and Hirth D. H. 1984. Behaviour. [In: White-tailed deer ecology and management. L. K. Halls, ed]. Stackpole Books, Harrisburg, PA: 129-168. 
Matschke G. H., deCalesta D. S. and Harder J. D. 1984. Crop damage and control. [In: White-tailed deer ecology and management. L. K. Halls, ed]. Stackpole Books, Harrisburg, PA: 647-654.

Mohr C. O. 1947. Table of equivalent populations of North American small mammals. Amer. Midl Nat. 37: 223-249.

Nelson M. E. and Mech L. D. 1992. Dispersal in female white-tailed deer. J. Mammal. 73: 891-894.

Nugent G. 1988. Successful control of fallow deer by recreational hunters in the Blue Mountains, Otago. N.Z. J. For. Sci. 18: 239-252.

Nugent G. and Mawhinney K. 1987. Recreational hunters' views of fallow deer management in the Blue Mountains, Otago. N. Z. J. For. 32: 32-35.

Putman R. J. 1986. Grazing in temperate ecosystems: Large herbivores and the ecology of the New Forest. Croom Helm, Beckenham, Kent: 94-97.

Putman R. J. 1989. Introduction: Mammals as pests. [In: Mammals as pests. R. J. Putman, ed]. Chapman \& Hall, London: 1-20.

Ratcliffe P. R. 1989. The control of red and sika deer populations in commercial forests. [In: Mammals as pests. R. J. Putman, ed]. Chapman \& Hall, London: 98-115.

Robinson R. C., Phillips P. H., Stevens G. and Storm P. A. 1989. An outbreak of Mycobacterium bovis in fallow deer. Aus. Vet. J. 66: 195-197.

Stérba O. and Klusak K. 1984. Reproductive biology of fallow deer, Dama dama. Acta. Sci. Nat. Brno 18: $1-46$.

Staines B. W. 1974. A review of factors affecting deer dispersion and their relevance to management. Mammal Rev. 4: 79-91.

Wardle J. A. 1984. The New Zealand beeches: ecology, utilisation and management. New Zealand Forest Service, Christchurch: 203-235.

Received 30 August 1993, accepted 4 January 1994. 